\title{
A ALOCAÇÃo DE RISCOS E A SEGURANÇA JURÍDICA NA PROTEÇÃo DO INVESTIMENTO PRIVADO
}

\author{
RISK ALLOCATION AND LEGAL CERTAINTY IN THE PROTECTION OF PRIVATE \\ INVESTMENT
}

Fábio Ulhoa Coelho

Mestre, Doutor e Livre-docente em Direito pela Pontifícia Universidade Católica de São Paulo. Professor titular da Pontifícia Universidade Católica de São Paulo.

E-mail: ulhoa@ulhoacoelho.com.br

Recebido em: 21/11/2016

Aprovado em: 20/02/2017

Doi: $10.5585 / \mathrm{rdb} . v 16 \mathrm{i} 7.542$

\begin{abstract}
RESUMO: O objetivo principal deste artigo é contribuir na formulação de um sólido conceito de segurança jurídica para fins de proteção jurídica do investimento privado. A ausência de um conceito de segurança jurídica tem tornado estéreis as discussões em torno de várias soluções legais e judiciais que impactam a atração de investimentos pelo país. O artigo propõe a construção do conceito no campo do direito comercial (e, em especial, em se tratando de proteção jurídica do investimento privado), em torno de dois cortes sucessivos: previsibilidade das decisões judiciais e efetividade da alocação de riscos, legais ou contratuais.
\end{abstract}

Palavras-Chaves: Proteção jurídica do investimento privado. Segurança Jurídica. Direito Comercial.

\begin{abstract}
The main purpose of this article is to contribute to the formulation of a solid concept of legal certainty for the purpose of legal protection of private investment. The absence of such a concept has made sterile the discussions about various legal and judicial solutions about the attraction of investments by the country (Brazil). This article offers a way to build that concept in the field of commercial law (and particularly in the case of legal protection of private investments), around these subjects: the predictability of judicial decisions and the effectiveness of legal or contractual risk allocation.
\end{abstract}

Key words: Legal protection of private investments. Legal Certainty. Commercial Law.

SUMÁRIO: Introdução; 1. Previsibilidade das decisões judiciais; 2. Insegurança jurídica como Desalocação de Riscos; 2.1. Personalidade jurídica própria das sociedades integrantes de grupo; 2.2. Garantia bancária à primeira demanda; 2.3. Contratos de colaboração empresarial; Conclusão: A importância da segurança jurídica do ambiente de negócios; Bibliografia. 


\section{INTRODUÇÃO}

Pode-se situar em 1955 o surgimento da teoria da desconsideração da personalidade jurídica, tomando-se o marco referencial da apresentação, por Rolf Serick, de sua tese para a obtenção do título de Privatdozent, na Universidade de Tübigen ${ }^{(1)}$. No Brasil, nos últimos trinta anos, é imensurável a quantidade de julgados que invocam esta teoria, para imputar aos sócios responsabilidade pelo pagamento de obrigação da sociedade empresária. Na Justiça do Trabalho, por exemplo, pode-se dizer que em todas as execuções direcionadas contra sociedades, os juízes invocam a desconsideração da autonomia patrimonial, para, sem maiores indagações, determinar a penhora de bens do patrimônio dos sócios. Ignoram-se, na significativa maioria destas decisões judiciais, os pressupostos da teoria da desconsideração. Abstrai-se, em última análise, o caráter verdadeiramente excepcional do afastamento da personalidade jurídica da sociedade, tornando regra geral o que deveria ser criteriosamente episódico.

Só para se estabelecer um termo de comparação, em dois países nórdicos (Suécia e Finlândia), a desconsideração da personalidade jurídica era considerada uma simples teoria doutrinária, sem repercussão judicial ("law in books"), até dezembro de 2014 e março de 2015, respectivamente. Quer dizer, nessas jurisdições, a primeira decisão judicial desconsiderando a autonomia patrimonial de sociedades, segundo a Durchgriffslehre, demorou mais de meio século. Em todas as oportunidades anteriores em que havia sido invocada, a teoria teve a aplicação negada. O primeiro julgamento a acolhê-la, tanto na justiça sueca como na finlandesa, apegou-se estritamente aos pressupostos da artificialidade da constituição da sociedade, reforçando o caráter excepcional e episódico da superação da autonomia patrimonial ${ }^{(2)}$.

Imagine-se, então, um investidor global comparando dois ambientes possíveis de negócios para decidir onde aportar investimentos - o Brasil e um destes países nórdicos. Ao considerar o quesito segurança jurídica, certamente notará uma enorme diferença. Aqui, nas últimas três décadas, a teoria da desconsideração da personalidade jurídica tem sido largamente aplicada sem critério, equivalendo sua compreensão pelos juízes, em muitos casos, à despersonalização mesmo das sociedades empresárias, ou seja, à completa ineficácia do instrumento de segregação de riscos esperada do instituto da pessoa jurídica. Lá, bastou uma única decisão (em mais de 50 anos de teoria) para, malgrado sua consistência técnica e manifesta natureza excepcional, advogados se preocuparem com os riscos a que estaria exposta a limitação da responsabilidade dos acionistas.

Na economia globalizada, os países competem pelos investidores globais, valendo-se, entre outros instrumentos, de seu direito comercial. Se ele, enquanto conjunto de normas de proteção do investimento privado, não inspira segurança, é natural que, neste quesito, outras jurisdições acabem se mostrando mais atraentes, pelo menos aos investimentos conservadores. $\mathrm{Na}$ agenda de desenvolvimento brasileira, por isso, não é possível desconsiderar-se a questão do aumento da segurança jurídica do direito comercial como um dos meios de atração de investimentos.

Mas, afinal, o que é segurança jurídica?

A segurança jurídica é talvez o menos estudado dos imperativos ${ }^{(3)}$. Como ocorre com alguma frequência na argumentação jurídica, os operadores do direito mais intuem que

\footnotetext{
${ }^{1}$ A pesquisa foi desenvolvida no semestre de inverno de 1952/1953, e a primeira edição da tese publicada em março de 1955 (Rechtsform und Realität juristischer Personen. $2^{\mathrm{a}}$ edição. Tübigen: Mohr, 1980, Vorwort).

${ }^{2}$ Cfr. MÅRTEN KNUTS e THOMAS KOLSTER. Supreme Courts in the nordics pierce the corporate veil - is the limited liability of the shareholders at risk? Em "Business Law International". London: International Bar Association, vol. 17(3), pgs. 253/258.

3 No rigor da técnica, a segurança jurídica não pode ser categorizada como "princípio", a exemplo da proporcionalidade ou da dignidade da pessoa humana. Sendo princípio uma espécie de norma, é indisputável que há decisões judiciais que não o aplicam. As normas são, por definição, aplicáveis nas situações fáticas a que se reportam Revista de Direito Brasileira | São Paulo, SP | v. 16 | n. 7 | p. 291 - 304 | jan./abr. 2017
} 
raciocinam, ao afirmarem que determinada solução (no âmbito jurisdicional ou legislativo) gera insegurança jurídica. Se instados a maiores digressões, não progridem, em razão da inexistência de um conceito assentado. Construí-lo ou pelo menos fixar as bases para sua formulação é, portanto, passo necessário a qualquer reflexão mais consistente sobre as soluções legais e judiciais passíveis de melhorar nosso ambiente de negócios. Afinal, não raramente argumentações antagônicas sustentam que a mesma solução gera e não gera segurança jurídica, sendo impossível lograr-se a superação do impasse enquanto inexistir conceito sedimentado acerca de cujo objeto divergem os argumentos.

A complexidade em torno do imperativo é grande. Abordado pelo ângulo da sensação de segurança, por exemplo, a discussão poderia acabar se enraizando até mesmo em questões de fundo psicológico. Assim, para avançar no tratamento do tema, duas premissas devem ser adotadas. De um lado, é preciso descartar, à partida, a noção repetitiva e infundada (verdadeiro clichê) da unidade do direito, reconhecendo-se sua pluralidade. Em consequência, cada ramo jurídico ou, no máximo, cada grupo de ramos próximos, terá seu próprio conceito de segurança jurídica ${ }^{(4)}$. Se para o direito comercial, como pretendo sustentar, o cerne se encontra na efetividade da alocação de riscos, para segmentos como o tributário ${ }^{(5)}$, constitucional ${ }^{(6)}$, administrativo ${ }^{(7)}$, a mesma abordagem se revelaria infrutífera. Se cogitarmos de ramos como família ou penal, ademais, resultará ainda mais pertinente a singularidade da efetividade da alocação dos riscos como núcleo do imperativo apenas para alguns poucos ramos jurídicos, entre os quais o direito comercial. De outro, impõe-se recortar o objeto, para tornar operacional o

e necessariamente não aplicáveis nas demais. Para algo ser uma norma jurídica, é necessário que se possa visualizar um sem-número de situações fáticas em que ela é inaplicável. O que sempre estiver presente na aplicação do direito é algo diverso de norma e, portanto, não pode ser um princípio. É assente que, na sociedade democrática dos nossos tempos, segurança jurídica, proporcionalidade e dignidade da pessoa humana devem acompanhar sempre qualquer aplicação do direito. Seria um despropósito admitir-se a pertinência de decisões inseguras, desproporcionais ou indignas para o ser humano. Logo, não se trata de princípio, mas de atributo diverso do direito. Como denominá-lo? Os autores dedicados ao tema, embora ressaltando a natureza meramente semântica da discussão, propõem alternativas diversas. ROBERT ALEXY vale-se da expressão "máxima” (Teoria dos direitos fundamentais. Tradução de Virgílio Afonso da Silva. São Paulo: Malheiros, 2008, pgs. 116/118). HuMBERTo ÁviLA denomina a categoria de "postulado normativo aplicativo" (Teoria dos princípios - da definição à aplicação dos princípios jurídicos. 13 edição. São Paulo: Malheiros, 2012, pgs. 156/158.). VIRGíliO AFONSO DA SILVA classifica a proporcionalidade como "regra", por não identificar nela as características próprias das normas principiológicas (Direitos Fundamentais conteúdo essencial, restrições e eficácia. $2^{\mathrm{a}}$ edição. São Paulo: Malheiros, 2010, pgs. 167/168). Para ANDRÉ RAMOS TAVARES, um "critério" (Curso de direito constitucional. 6a edição. São Paulo: Saraiva, 2008, pg. 708). Minha preferência é por "imperativo".

${ }^{4}$ A presente reflexão parte, portanto, de premissa bastante diversa da adotada pelo estudo mais alentado sobre a segurança jurídica na literatura nacional, de autoria de HUMBERTO ÁvILA, para quem é possível construir-se um conceito de segurança jurídica para todos os ramos do direito, em torno das noções de confiabilidade, inteligibilidade e previsibilidade (Teoria da segurança jurídica. $3^{\text {a }}$ edição. São Paulo: Malheiros, 2014).

5 Em obra coordenada por IVES GANDRA DA SILVA MARTINS, que registra o $41^{\circ}$ Simpósio Nacional de Direito Tributário (Segurança jurídica em matéria tributária. Porto Alegre: Lex Magister - CEU-IICS, 2016), indagou-se a vários tributaristas, qual seria "o conceito de segurança jurídica em matéria tributária". Nas respostas, o núcleo do conceito é buscado na legalidade formal (pg. 35), nos atributos do enunciado normativo (pgs. 71 e 148), proteção de expectativas de confiança legítima (pgs. 86 e 119), neutralização de surpresas (pg. 103), necessidade de estabilidade (pgs. 127 e 200), regularidade estrutural e funcional (pg. 179), entre outros. A seu turno, RoQUE CARRAZZA associa segurança jurídica à tipicidade fechada, exclusivismo, vinculação do lançamento à lei, interpretação estrita da lei, igualdade, confiança na lei fiscal, boa-fé do contribuinte e livre acesso ao Judiciário (Curso de direito constitucional tributário. 22 a edição. São Paulo: Malheiros, 2006, pgs. 413/439).

${ }^{6}$ GILMAR MENDES problematiza a segurança jurídica em vista da "revisão radical de determinados modelos jurídicos ou adoção de novos sistemas ou modelos" (Curso de direito constitucional. Em coautoria com Inocêncio Mártires Coelho e Paulo Gustavo Gonet Branco. $3^{a}$ edição. São Paulo: Saraiva, 2008, pg. 487). AndrÉ RAMOS TAVARES considera central à segurança jurídica o "direito à estabilidade mínima da ordem jurídica” (Obra citada, pg. 758).

${ }^{7}$ SÉRGIO FERRAZ e ADILSON ABREU DALLARI elegem os vetores da certeza e estabilidade (Processo administrativo. $3^{a}$ edição. São Paulo: Malheiros, 2012, pg. 116). SÍlvio LuIS FERREIRA DA RochA menciona a necessidade de estabilidade "na regência da vida social” (Manual de direito administrativo. São Paulo: Malheiros, 2013, pg. 93).

Revista de Direito Brasileira | São Paulo, SP | v. 16 | n. 7 | p. 291 - 304 | jan./abr. 2017 
conceito. E dois recortes têm cabimento: a segurança jurídica deve ser reduzida inicialmente à previsibilidade das decisões judiciais; e, em seguida, à efetividade da alocação dos riscos. $\mathrm{O}$ objetivo é conferir racionalidade às discussões em torno do potencial lesivo à segurança jurídica associado a certa solução: que os favoráveis mostrem como ela viabilizaria que os riscos sejam suportados por quem os assumir; e que os contrários contra-argumentem apontando como a mesma solução pouparia quem assumiu o risco de o suportar e, consequentemente, sua desalocação. Sem esta concretude, o debate continuará estéril.

Este artigo tem o objetivo de contribuir para o aclaramento das bases teóricas de sustentação do conceito de segurança jurídica no direito comercial, entendido este como o ramo do direito concernente à proteção jurídica do investimento privado. Além desta breve introdução, numerada como primeira, ele se desdobra em três outras seções. A segunda seção realiza um corte inicial no objeto, reduzindo a segurança jurídica à previsibilidade das decisões judiciais. A terceira faz novo corte, para examinar o tema da assunção dos riscos, derivada da lei ou do contrato. Procura, ademais, aprofundar o exame da desalocação de riscos, por meio de três figuras do direito comercial: grupo de sociedades, garantia à primeira demanda e contratos de colaboração. Uma (também breve) conclusão se encontra na quarta seção.

\section{PREVISIBILIDADE DAS DECISÕES JUDICIAIS}

O primeiro corte no objeto, para a construção do conceito de segurança jurídica, reduz esta à previsibilidade das decisões judiciais. A relação é direta: quanto mais previsíveis forem as decisões judiciais, mais seguro é o ambiente de negócios. Se a interpretação imediata das normas gerais e abstratas costuma ser confirmada na quase totalidade das decisões judiciais, os agentes econômicos podem orientar suas decisões em função de cenários construídos a partir destas normas, porque eles tendem a antecipar o que acontecerá com alto grau de acerto. A fidelidade e eficácia dos cenários e os acertos dos cálculos dos agentes econômicos dependem da generalizada confirmação pelos juízes da interpretação imediata das normas do direito positivo.

Em suma, no ambiente de negócios em que a interpretação imediata das normas jurídicas é geralmente confirmada pelos juízes, há elevado nível de previsibilidade das decisões judiciais e, em decorrência, segurança jurídica. Se, no entanto, esta confirmação generalizada da interpretação imediata das normas gerais e abstratas não se verifica, o ambiente de negócios não tem segurança jurídica porque a imprevisibilidade das decisões judiciais nega aos agentes econômicos os instrumentos confiáveis para orientar suas decisões. Estas são tomadas, pode-se dizer, mais ou menos "no escuro".

Antes de avançar, cabe chamar a atenção a dois aspectos deste corte, até aqui empreendido. Refiro-me à qualificação da interpretação a confirmar como "imediata" e à da confirmação como "generalizada". Estes adjetivos precisam ser explicados.

Em relação à interpretação, pode-se distinguir, de um lado, a resultante da leitura atenta e técnica do dispositivo em que se encontra a norma jurídica, sem maiores digressões ou contextualizações. É a interpretação imediata porque, numa imagem, nada se imiscui entre o dispositivo e o sentido que ele denota a uma pessoa esclarecida e até mesmo à generalidade dos profissionais do direito. De outro lado, estão interpretações da mesma norma jurídica que vão além do dispositivo para encontrarem sentidos diversos do resultante da leitura atenta e técnica. Elas não são imediatas, mas, ao contrário, mediatizadas por argumentos mais ou menos complexos. Resultam de processos argumentativos como a exegese conforme a constituição, hermenêutica sistemática, ponderação em torno de princípios, por vezes implícitos, colmatação de lacunas e mesmo o questionamento da constitucionalidade, ou seja, interpretações que buscam elementos em outros repertórios do direito para sustentar que a norma em vigor não é a que a maioria das pessoas e profissionais consegue ler no dispositivo, mas diversa. 
A imprevisibilidade das decisões judiciais decorre da profusão, em juízo, das interpretações mediatizadas, isto é, da não confirmação pelo Poder Judiciário daquilo que as normas gerais e abstratas sugerem ser o direito vigente. Ativismo judicial e mesmo a mera atuação deliberadamente criativa de alguns magistrados interessados em "deixarem sua marca" são alguns dos fatores responsáveis pelo exponencial impulso a essa profusão perniciosa ao ambiente de negócios.

Em relação à generalidade da confirmação cabe ressalvar que o ambiente de negócios com segurança jurídica não depende da absoluta previsibilidade das decisões judiciais, de resto impossível. Na verdade, seria ilusório e irreal pretender antecipar, com 100\% de certeza, o resultado das demandas judiciais. Em outros termos, há sempre uma margem tolerável de imprevisibilidade com a qual devem se conformar os agentes econômicos. Empresários devem sempre computar em seus cálculos uma (pequena) probabilidade de uma ou outra decisão afastarse da direção apontada pelas normas gerais e abstratas. Insegurança jurídica passa a existir quando esta "imprevisibilidade previsível" deixa de ser marginal e se espraia a ponto de comprometer cálculos conservadores.

Deste modo, segurança jurídica se encontra no ambiente de negócios em que a generalidade das decisões judiciais (mas não todas) confirma a interpretação imediata das normas gerais e abstratas, isto é a não mediatizada por argumentos mais ou menos complexos que fundamentam sentidos não resultantes da leitura atenta e técnica do dispositivo.

Feitas estas precisões conceituais, retome-se a questão da relevância da previsibilidade das decisões judiciais na orientação das decisões pelos agentes econômicos. Centre-se num dos agentes, o empresário; e numa de suas decisões mais importantes, a precificação dos produtos ou serviços que oferece ao mercado. Como as decisões, num ambiente de negócios marcado pela insegurança jurídica, é tomada mais ou menos "no escuro", o empresário terá que adotar certas cautelas. Isto é, ele precisará ter uma prudência a mais, do que teria caso estivesse operando num ambiente diverso, com segurança jurídica.

Afinal, o empresário precisa se precaver para a hipótese de ter a receita reduzida (em razão de liberação do outro contratante de uma obrigação contratada, total ou parcialmente), ou os custos majorados (com a imputação de obrigações que ele não suspeitava ter), por conta de decisão judicial que confira à lei interpretação diversa da imediata. O modo de o empresário se acautelar frente a estas variáveis (que podem consumir toda a margem de lucros ou mesmo leválo à quebra) consiste elevar os preços de seus produtos ou serviços. Em termos mais técnicos, o empresário irá acrescer aos seus preços uma taxa de risco associada à imprevisibilidade das decisões judiciais.

Em geral, ao empresário é relativamente indiferente a extensão da obrigação imposta pela lei. Projetará cenários e fará cálculos a partir dela, na expectativa de que nada lhe será subtraído na receita ou acrescido aos custos além do previsto nas normas gerais e abstratas.

Se, por exemplo, o direito positivo obriga o representado a elevados pagamentos em favor dos representantes comerciais, no caso de rescisão do contrato de representação, mas nada estatui em relação ao colaborador na venda direta, o empresário faz seus cálculos e decide pelo modelo de escoamento de mercadorias mais interessante para ele. Se lhe parecer que poderá vender seus bens mais baratos (com mais competitividade, portanto) adotando o modelo de venda direta, irá preferi-la à representação comercial. O que verdadeiramente prejudica o investimento é o Judiciário, anos após estes cálculos, por meio de uma interpretação mediatizada da lei, decidir que o colaborador na venda direta titula os mesmos direitos do representante comercial. O empresário justamente indignado protesta (em vão): por que não foi "avisado" disto antes? Teria feito outras contas, considerado este custo, optado pela representação comercial ou, se mantivesse a opção da venda direta, teria praticado preço mais alto e preservado a sua margem de lucro. 
Note-se que não cabe exigir do empresário outra prática senão a de embutir em seus preços a taxa de risco associada à imprevisibilidade das decisões judiciais. Administra mal a empresa aquele que, num ambiente de negócios caracterizado por certo risco, deixa de considerálo na precificação dos produtos ou serviços por ela fornecidos. Se o grau tolerável de imprevisibilidade previsível foi ultrapassado, os administradores das empresas atuantes no correspondente ambiente de negócios só cumprem seu dever legal de diligência (LSA, art. 153; $\mathrm{CC}$, art. 1.011), se praticarem esta taxa de risco.

A taxa de risco associada à imprevisibilidade das decisões judiciais aumenta os preços dos produtos e serviços, penalizando os consumidores. A competição empresarial não serve de freios a este aumento porque, estando todos os empresários expostos ao mesmo risco, é inevitável sua ampla generalização nas práticas empresariais.

Encerro este item anotando que decisões judiciais imprevisíveis não são sempre indesejadas. Pelo contrário, a evolução do direito faz-se também a partir de decisões que não confirmam a interpretação imediata da norma geral e abstrata. Evoluções como a do reconhecimento da constitucionalidade do casamento entre pessoas do mesmo sexo, por exemplo, são frutos de desconfirmações desta natureza. Por isso, a construção do conceito de segurança jurídica no âmbito do direito comercial reclama mais um recorte. Ver a segurança jurídica como alto grau de previsibilidade das decisões judiciais é pertinente, mas mantém a discussão ainda num plano excessivamente abstrato. Para diminuir o grau de abstração, deve-se distinguir o conteúdo específico das decisões judiciais imprevisíveis que põe em risco a segurança jurídica do ambiente de negócios.

\section{INSEGURANÇA JURÍDICA COMO DESALOCAÇÃO DE RISCOS}

Desalocação ocorre quando um empresário suporta risco que não assumiu, simultaneamente à liberação, pelo juiz, de outro empresário de suportar risco que havia assumido. São duas faces indissociáveis da mesma equação. Não é possível poupar um empresário de qualquer risco assumido sem necessária e concomitantemente o transferir a outro, que não o assumira.

A assunção de risco pode decorrer da lei ou de contrato. Sempre que alguém se torna empresário ou um empresário inicia nova empresa, inevitavelmente chama para si determinados riscos. Não há atividade empresarial certamente fadada ao sucesso. Por mais engenhoso, prudente e competente que seja o empresário, sua atividade pode simplesmente não dar certo. Por vezes, até mesmo sem explicação racional. Os potenciais adquirentes ou consumidores apenas não se interessam pelo produto ou serviço oferecido pelo empresário. Deste modo, a simples decisão de tornar-se empresário ou iniciar nova empresa corresponde à de assumir riscos. O fundamento desta assunção é legal, porque não há nenhum contrato especificamente relacionado à hipótese. Por outro lado, há os riscos assumidos em decorrência de negócios jurídicos (declarações em títulos de crédito, em atos societários ou em contratos). Aqui o fundamento pode ser chamado de contratual, identificando-se de modo específico uma declaração de vontade em torno da assunção do risco.

Note-se que o risco empresarial é sempre uma decorrência da vontade de quem o assume. Mesmo nos decorrentes da lei, o sujeito que assume o risco irá suportá-lo porque quer ser empresário, porque deseja lucrar com os frutos da empresa e se empenha consciente e decisivamente para viabilizá-la e desenvolvê-la. Há riscos que assumimos sem vontade (vários dos relacionados à saúde, por exemplo); mas ninguém pode alegar que, por alguma razão, tinha sido forçado a assumir riscos empresariais. Isto não existe, juridicamente falando.

Para o direito comercial, segurança jurídica é a efetivação judicial da alocação, legal ou contratual, dos riscos. Quando se pode, de modo geral, nutrir a racional expectativa de que o Poder Judiciário irá efetivar a alocação dos riscos, segundo o prescrito na lei ou previsto nos 
contratos, esta previsibilidade das decisões judiciais torna o ambiente de negócios juridicamente seguro.

\subsection{Personalidade jurídica própria das sociedades integrantes de grupo}

As sociedades integrantes de grupo, mesmo que de direito, conservam sua personalidade jurídica própria e seus patrimônios autônomos (LSA, art. 266, in fine). Em razão desta regra, quem concede crédito a sociedade integrante de grupo pode considerar apenas o risco-sociedade, não precisando avaliar o risco-grupo (excluem-se deste padrão as instituições financeiras, pelas razões que logo mais se esclarecem). Sendo cada sociedade integrante de grupo uma pessoa jurídica com autonomia patrimonial, decorre desta alocação legal de riscos que se a sociedade devedora for solvente, seus credores não podem ser prejudicados pela eventual insolvência de uma ou mesmo de todas as demais sociedades do mesmo grupo.

Evidentemente, quando a lei assegura a autonomia patrimonial de cada sociedade integrante do grupo, tal mecanismo de alocação de riscos possibilita o barateamento do crédito, sempre que o risco-sociedade for menor que o risco-grupo. Esta, aliás, tende a ser a hipótese mais corriqueira, com a criação de subsidiárias dedicadas a atividades econômicas ou mesmo empreendimentos específicos.

A avaliação centrada no risco-sociedade não é admissível para as instituições financeiras desde 2000, em decorrência de umas medidas de saneamento das instituições financeiras adotadas no governo FHC. De acordo com as regras vigentes, sobre a avaliação de risco de operações de crédito bancário para fins de provisionamento ${ }^{(8)}$, a autonomia patrimonial das sociedades integrantes de grupo é desconsiderada. O regulamento baixado pelo CMN estabelece que, em geral, todas as operações de crédito do banco com as sociedades de um mesmo grupo econômico devem ser classificadas no nível da operação "que apresentar maior risco". É aberta a possibilidade de excepcionalmente isolar-se determinada operação, para classificá-la em consideração de sua natureza e finalidades, características das garantias e valor, mas não em função especificamente da pessoa jurídica mutuária (Res. BACEN n. 2.682/99, art. $3^{\circ}$ ). Em outros termos, no mais das vezes, a boa e regular administração bancária não pode considerar, na concessão de crédito a sociedade integrante de grupo, o risco-sociedade, mas deve levar em conta somente o risco-grupo.

As consolidações substanciais que se multiplicam nas recuperações judiciais requeridas por sociedades do mesmo grupo, em litisconsórcio ativo, quando referendadas pelo Poder Judiciário na apreciação de recursos de credores insatisfeitos com a deliberação da assembleia, acabam por generalizar o conceito de que também para as empresas não-financeiras, o mais

\footnotetext{
${ }^{8}$ De acordo com JORGE KATSUMI NIYAMA e AMARO L. OliVEIRA GOMES, “a constituição de provisão para créditos de liquidação duvidosa representa, em qualquer empresa, uma estimativa de perda provável dos créditos, em atendimento aos princípios fundamentais de contabilidade, em especial ao da realização da receita e confrontação com a despesa e ao da prudência ou conservadorismo. Ocorre que, nos bancos e demais instituições financeiras, sua constituição apresenta características específicas que obrigam esses estabelecimentos a adotarem procedimentos diferenciados em relação aos praticados pelas demais empresas (comerciais, industriais ou de prestação de serviços), principalmente em função das seguintes razões: (a) o ativo a ser provisionado representa um crédito a receber decorrente, usualmente, de empréstimo, ou seja, a 'matéria prima' utilizada por essas entidades é o próprio dinheiro; (b) o ativo objeto de provisionamento, normalmente, é recebido em diversas parcelas, diferentemente de uma duplicata a receber, e representa parcela significativa, quando comparado com o patrimônio líquido, à medida que os bancos operam com captação de recursos de terceiros. Considerando que o principal 'produto' à venda pelos bancos e demais instituições financeiras é sua imagem perante o público (credibilidade e reputação) e que, para honrar seus compromissos com os depositantes, é necessário que seus ativos sejam tempestivamente realizáveis em caixa, o dimensionamento adequado da referida provisão, que permita, entre outros aspectos, avaliar o nível de risco, é de extrema importância para os diversos usuários da informação contábil (entre eles, certamente, os depositantes)" (Contabilidade de instituições financeiras. São Paulo: Atlas, 2000, pgs. 75/76).
} 
adequado, sob o ponto de vista da boa e regular administração da concessão de crédito, é a completa irrelevância do risco-sociedade, devendo se levar em conta sempre o risco-grupo.

Verifica-se a desalocação do risco, porque se o empresário não financeiro for guiar suas avaliações a partir do que dispõe o art. 266 da LSA, racionalmente tenderá a isolar a sociedade a quem concede crédito do restante do seu grupo. Tal isolamento é racional até mesmo como meio de baratear o crédito, já que serão bem menos abrangentes as pesquisas e tratativas na negociação deste. Quando for surpreendido com a desconsideração da personalidade jurídica própria da sociedade devedora, num processo de recuperação judicial do grupo, por exemplo, o empresário estará suportando um risco potencialmente maior do que o assumido. Já os credores das demais sociedades do grupo, estarão sendo em parte poupado do risco que assumiram, ao também o avaliarem a partir do art. 266 da LSA.

\subsection{Garantia bancária à primeira demanda}

As garantias bancárias à primeira demanda disseminaram-se no comércio internacional, no contexto da crise do petróleo de 1973, e, já há tempos, têm sido largamente aproveitadas nas demais relações interempresariais internas. Consistem no que se convencionou chamar de garantia autônoma. Trata-se de declaração, feita normalmente por instituição financeira ou seguradora (garante), de que pagará, como principal devedor, dentro de determinado limite, quantia devida por um empresário (garantido) a outro (favorecido). Denomina-se autônoma esta garantia porque, ao contrário da fiança, não é negócio jurídico acessório. Deste modo, na garantia autônoma, o garante não pode recusar o pagamento ao favorecido, alegando exceções eventualmente titularizadas pelo garantido ${ }^{(9)}$.

Em razão de sua autonomia, de não ser acessória de outro negócio jurídico, a garantia autônoma confere maior segurança e celeridade ao crédito derivado de relação interempresarial (10). O favorecido demanda o pagamento do garante, que deve realizá-lo de pronto, sem maiores perquirições. Em estando o valor demandado pelo favorecido dentro do limite da declaração, o garante realiza o pagamento e depois, em regresso, cobra do garantido. Este, mesmo que eventualmente tenha alguma razão para questionar a obrigação, não pode se recusar a pagar ao garante. Deve pagá-lo e, posteriormente, promover a ação cabível contra o favorecido, para ser indenizado, caso seja consistente a razão que alega possuir contrariamente à existência da obrigação.

O mecanismo associado à garantia autônoma é, então, esquematicamente, o seguinte: (a) o garante, assim que solicitado pelo favorecido, paga o valor demandado, podendo recusar o

\footnotetext{
${ }^{9}$ De acordo com a definição de MONICA JARDIM: “A garantia autônoma, igualmente conhecida por garantia pura, incondicional, abstrata, independente, ou por garantia (bancária) automática, à primeira solicitação, à primeira interpretação ou de pagamento imediato, trata-se de um tipo de garantia que, na fórmula mais comum, é prestada por uma entidade, normalmente um banco, que se obriga a entregar, a pedido de um terceiro, uma soma pecuniária previamente acordada, ao beneficiário da garantia, logo que este prove o incumprimento de determinado contrato por parte do terceiro (contrato autônomo de garantia simples) ou de imediato, quando este simplesmente o interpele a realizar essa prestação (contrato autônomo de garantia automática ou 'à primeira solicitação'), mas abdicando desde logo, em ambos os casos, a opor ao beneficiário quaisquer exceções derivadas tanto da sua relação com o terceiro garantido, como da relação jurídica cujo cumprimento garante" (A garantia autônoma. Coimbra: Almedina, 2002 pg. 13). Conferir, também, VASCO SOARES DA VEIGA: "caracterizam-se [as garantias bancárias autônomas] por o banco dever pagar logo que o pagamento lhe é exigido pelo beneficiário, que se limita a comunicar o incumprimento da obrigação (principal) do mandante, pelo que o banco não pode formular quaisquer objeções" (Direito bancário. Coimbra: Almedina, 1994, pg. 263).

${ }^{10}$ No dizer autorizado de ARNOLDO WALD: "a existência da obrigação autônoma e abstrata exigível à primeira demanda aumenta a segurança do credor em virtude da ruptura da relação da causalidade entre a garantia e o contrato garantido, destacando-se e isolando-a das demais relações jurídicas que constituem a sua razão de ser" (A garantia à primeira demanda no direito comparado. Em "Revista de Direito Mercantil" vol. 66. São Paulo: RT, abril-junho 1987, pg. 6).
} 
pagamento se ultrapassado o valor da garantia; (b) o garantido, assim que solicitado pelo garante, reembolsa o montante despendido por este; (c) se o garantido tem alguma exceção a opor ao favorecido, cabe a ele promover a ação judicial, provando o que alega, para ser indenizado. Este mecanismo não é prejudicial ao garantido. Ao concordar com a outorga de garantia autônoma, concordou também em se submeter a esta sistemática de solução de potenciais conflitos de interesses.

Instrumento de reforço do cumprimento de obrigações contratuais entre empresários, de grande eficiência, a garantia autônoma foi instituto disciplinado legalmente por poucos países (os hoje inexistentes Tchecolosvaquia, República Democrática da Alemanha e Iugoslávia ${ }^{(11)}$ ). Representa, assim, no mundo todo, um contrato atípico. O direito brasileiro, que reconhece expressamente a validade e eficácia dos contratos atípicos (CC, art. 425), alberga a garantia autônoma. Embora não abundem estudos doutrinários, nem precedentes jurisprudenciais, não há dúvidas de que se trata de negócio jurídico plenamente admissível pela nossa ordem jurídica.

Nas jurisprudências alemã, portuguesa e italiana, encontram-se decisões que liberaram o banco garante de proceder ao pagamento em alguns casos especialíssimos. Assim, apenas se dispõe de elementos consistentes comprobatórios de fraude do beneficiário ou mesmo do pagamento já ter sido feito pelo garantido, o banco pode se recusar a pagar o beneficiário. Mas, em respeito ao contratado pelas partes, não se admite a suspensão da garantia a pedido do garantido. Afinal, a essência deste contrato atípico está na impossibilidade de o garante recusar o pagamento da garantia em virtude de exceções eventualmente tituladas pelo garantido. Se um juiz determinasse a suspensão da garantia, a pedido deste, estaria negando eficácia à vontade declarada pelas partes, ao contratarem a garantia autônoma ${ }^{(12)}$.

Em razão desta sua marca fundamental, a garantia autônoma não se confunde com a fiança civil. Esta última é garantia acessória, de modo que, uma vez invalidada a obrigação principal, ela deixa de subsistir irremediavelmente. Na garantia autônoma, ao contrário, mesmo no caso de invalidação da obrigação garantida, remanesce a do garante ${ }^{(13)}$. Por isso, quando a fiança bancária prevê a cláusula à primeira solicitação, ou equivalente, o banco não pode ser impedido de cumprir sua obrigação de fiador, em razão de solicitação do afiançado. Trata-se exatamente da situação que este negócio jurídico pretende evitar, para maior segurança das relações entre os empresários. Diferentemente de uma fiança outorgada em função de obrigação civil, a bancária com a cláusula à primeira solicitação tem um único objetivo: o de estabelecer o pronto pagamento de um valor a um dos contratantes pelo banco. Se porventura houver alguma

\footnotetext{
${ }^{11}$ MONICA JARDIM, obra citada, pgs. 20/21.

${ }^{12}$ Discutindo a suspensão da garantia autônoma por ordens judiciais, HERMES MARCELO HUCK anota: "uma garantia efetivamente autônoma deve sobreviver à eventual nulidade, resilição ou extinção do contrato que pretenda garantir. A mera discussão da possibilidade de se atingir a garantia com a nulidade da obrigação dita principal, por si só já macularia seu conceito de perfeita autonomia. Essa independência da garantia em relação ao contrato ou obrigaçãobase caracteriza a autonomia da garantia oferecida" (Garantia à primeira solicitação no comércio internacional. Em "Revista de Direito Mercantil”, vol. 84. São Paulo: RT, outubro-dezembro de 1991, pg. 10).

${ }^{13}$ Segundo MONICA JARDIM: "traduzindo-se o conteúdo da fiança no cumprimento da obrigação do devedor principal, a acessoriedade é sua característica inevitável. Acessoriedade que significa que a existência, a validade e o conteúdo da obrigação principal condicionam a existência, a validade e o conteúdo da obrigação de fiança, no sentido de que, se a primeira se extingue, a segunda também se extingue, se a primeira é inválida, a segunda também o é, e de que o conteúdo desta não pode ser mais amplo que o da primeira. Em síntese, a obrigação do fiador, enquanto acessória, encontra-se face à do afiançado - a principal - numa relação de dependência ou subordinação. [...] Através da garantia autônoma, o garante, tal como o fiador, assegura a verificação de um certo resultado (v.g. o cumprimento pontual e correto da obrigação do devedor), responsabilizando-se pelo risco da não produção desse resultado. Por isso, a garantia autônoma, tal como a fiança, é uma garantia especial pessoal de cumprimento das obrigações. Mas, a responsabilidade assumida pelo garante é diferente da assumida pelo fiador; enquanto que a responsabilidade do fiador é acessória, em tudo igual à do devedor, a responsabilidade do garante é própria e autônoma, em tudo distinta da do devedor. Não se pode confundir aquilo que o garante assegura com a sua obrigação, com aquilo a que o garante se obriga. O garante não se obriga a cumprir a obrigação do devedor" (obra citada, pgs. 175 e 179/181).
}

Revista de Direito Brasileira | São Paulo, SP | v. 16 | n. 7 | p. 291 - 304 | jan./abr. 2017 
exceção arguível pelo afiançado, isto é questão a ser decidida, posteriormente, em ação judicial entre ele e o empresário garantido. Ao contratarem a concessão de uma fiança bancária, empresários declaram concordar com este mecanismo de garantia, que é bem diversa da fiança civil $^{(14)}$.

A garantia à primeira solicitação, como se pode perceber, é um mecanismo de alocação contratual de riscos. O devedor garantido concorda em chamar para si o risco de pagar em regresso ao banco garante, mesmo entendendo ter razões substanciais para não se considerar devedor. Assumiu o risco de ter que fazer este pagamento, ainda que indevido, cabendo-lhe, em seguida, demandar o credor para discutir a existência ou extensão da obrigação.

Quando o Poder Judiciário determina ao banco que suspenda o adimplemento da garantia à primeira solicitação, a pedido do devedor garantido, isto acarreta insegurança jurídica ${ }^{(15)}$. Notese que, mesmo havendo razões que prima facie apontem para a inexistência da obrigação, segundo alega o devedor garantido, não é o caso de o Poder Judiciário suspender a execução da garantia à primeira solicitação, porque isso implica poupar um agente econômico do risco que deliberadamente assumiu, desalocando-o mediante transferência a outro agente econômico que deliberadamente não o assumiu. Somente em situações excepcionais, como visto, em que é comprovada liminar e cabalmente a fraude na requisição de pagamento feita pelo garante, é que se admite a intervenção do juiz. Ela, contudo, faz-se não para desalocar o risco, mas somente para impedir a concretização de uma fraude. Afinal, neste caso, o risco restaria desalocado caso a garantia fosse fraudulentamente executada.

Não é preciso insistir que o credor, ao exigir a garantia à primeira solicitação, e, com isso, transferir ao devedor integralmente o risco de ter que pagar o devido e depois ir a juízo discutir a obrigação, precificou esta alocação, tornando o crédito concedido mais barato. A intervenção constante do Poder Judiciário desalocando os riscos por meio da ineficácia da cláusula à primeira solicitação acaba encarecendo o crédito. E, novamente, será o consumidor a arcar com este encarecimento, que, mais cedo ou mais tarde, é embutido nos preços dos produtos e serviços oferecidos no mercado de consumo.

\subsection{Contratos de colaboração empresarial}

Nos contratos de colaboração empresarial, o elemento nuclear se encontra na obrigação que um dos empresários contratantes assume, de criar, ampliar ou consolidar mercado para o produto ou serviço fornecido pelo outro. Este é o fornecedor, aquele, o colaborador. Trata-se de uma das modalidades contratuais visando a organização ou racionalização da cadeia de escoamento de mercadorias (distribuição, franquia, representação comercial etc) fabricadas ou comercializadas pelo fornecedor (distribuído, franqueador, representado etc) e que chegarão aos adquirentes ou consumidores graças à intermediação ou aproximação do colaborador (distribuidor, franqueado, representante etc) ${ }^{(16)}$. A diferença entre a colaboração empresarial e outros contratos também relacionados ao escoamento de mercadorias reside nesta obrigação assumida pelo colaborador. No fornecimento, por exemplo, o revendedor não a assume, embora

\footnotetext{
14 “O pagamento da garantia bancária, quando realizada com a cláusula ‘à primeira solicitação’ (first demand), independe de prévia consulta ao garantido. Deve ser feito em atendimento a simples pedido do titular da garantia. [...] o banco não pode negar o pagamento, já que a garantia foi dada com a cláusula 'à primeira solicitação'; também o cliente garantido não poderá negar-se a pagar o banco em regresso, tendo em vista as obrigações que assume ao contratar a garantia bancária, mas o titular responderá perante o garantido por exercício abusivo de direito, devendo indenizá-lo pelos prejuízos decorrentes da execução irregular da garantia bancária" (Meu Curso de direito comercial. $17^{\text {a }}$ edição. São Paulo: RT, 2016, vol. 3, pg. 144/145).

15 Cfr. MARIA CRISTINA VARALla MENDES e CAIO FARAH RODRIGUEZ. Notas sobre a alocação de riscos e garantias contratuais. Em Fundamentos e Princípios dos contratos empresariais. Coordenador Wanderley Fernandes. São Paulo: Saraiva-FGV, 2007, pgs. 407/708.

${ }^{16}$ Cfr. meu Curso... citado, pgs. 103/106.
}

Revista de Direito Brasileira | São Paulo, SP | v. 16 | n. 7 | p. 291 - 304 | jan./abr. 2017 
lhe seja altamente interessante contribuir para a criação, ampliação ou consolidação do mercado do produto que revende, porque isso lhe trará naturalmente mais vendas ${ }^{(17)}$. A diferença, ressalto, é que, nos contratos de colaboração, os investimentos do colaborador para criar, ampliar ou consolidar mercado para o produto fornecido são feitos para fins de cumprir uma obrigação contratada; no fornecimento, e em outros contratos de escoamento de mercadorias não classificáveis como de colaboração, eventuais investimentos do revendedor não decorrem do cumprimento de nenhuma obrigação contratada com o vendedor.

Esta diferença mostra sua relevância quando o contrato é extinto. Enquanto no fornecimento, nenhuma indenização é devida ao revendedor, pelos investimentos que eventualmente tiver feito, sendo risco exclusivo dele ter, ou não, oportunidade para recuperá-los, nos contratos de colaboração, é racional que o colaborador tenha acesso a meios, legais ou contratuais, de recuperação dos investimentos feitos. A propósito, em dois contratos de colaboração (a representação comercial e a concessão mercantil para a comercialização de veículos automotores terrestres), a lei assegura, na resolução ou resilição do contrato, determinadas prestações do fornecedor ao colaborador, com o objetivo de compensá-lo pela perda da oportunidade de continuar explorando o mercado que ajudou a criar, ampliar ou consolidar. Nos demais contratos de colaboração (distribuição, franquia, concessão atípica etc), se não quiser amargar perdas certas, o colaborador deve contratar um prazo mínimo de duração do vínculo contratual, que lhe permita recuperar os investimentos. Se errar neste ponto da negociação, não terá direito a nenhuma indenização em razão do fim do contrato; em outros termos, assumira risco demasiado grande e haverá de suportá-lo.

Um problema crucial para a devida alocação de riscos, e a consequente segurança jurídica no campo do direito comercial, surge em torno do art. 473, parágrafo único, do Código Civil. Trata-se de disposição geral da lei civil, em virtude do qual o contratante que houver feito investimentos de vulto está protegido pela postergação dos efeitos da resilição unilateral, por prazo "compatível com o vulto e a natureza dos investimentos". O objetivo da norma é compatibilizar o direito do contratante à dissolução do contrato por vontade unilateral, sempre que admissível pela lei ou contrato, mas impedindo que ele redunde em prejuízos de monta à outra parte $^{(18)}$. Na doutrina, os exemplos de incidência do dispositivo são construídos a partir de contratos de direito civil, assim o comodato e a corretagem de imóveis ${ }^{(19)}$, mas a interpretação imediata deste infeliz dispositivo sugere sua aplicação também aos contratos empresariais.

\footnotetext{
17 "No fornecimento, uma das partes se obriga a vender e a outra a comprar a coisa objeto de contrato, como em qualquer outra compra e venda. A nota particular do fornecimento é a prévia definição, pelo acordo de vontade dos contratantes, de uma ou mais condições de negócio. [...] A função do contrato de fornecimento é estabilizar determinados aspectos da relação negocial, poupando as partes de renegociações periódicas sobre eles e possibilitando o cálculo empresarial relativamente ao suprimento de insumos (para o comprador) ou garantia de demanda (para o vendedor). Não há nenhuma condição negocial da compra e venda que se encontre forçosamente em todo fornecimento; ao contrário, as condições negociais estabilizadas variam de contrato para contrato porque dependem apenas dos interesses convergentes dos contratantes. Assim, o fornecimento pode ser celebrado por prazo determinado ou indeterminado, com ou sem exclusividade, definindo ou não preço, procedimentos, periodicidade, quantidade e demais condições" (meu Curso... citado, pg. 84).

${ }^{18}$ Para RUY Rosado DE AGUIAR JR., "são dois os interesses em jogo. Se, de um lado, as partes devem conservar a sua liberdade de dar por findo um negócio sem prazo determinado, e ultimar essa pendência o mais rapidamente possível, de outro, impende considerar que a extinção da relação pode significar, além do fim da fonte exclusiva de renda do cocontratante, ainda a interrupção mais ou menos abrupta dos negócios que está a realizar com terceiros. A boa-fé e o princípio da função social do contrato fornecerão sólidos subsídios para a solução adequada a cada caso, a fim de salvaguardar os interesses de ambas as partes. Sendo uma fonte constante de litígios, é conveniente que as partes incluam no contrato dispositivos regulando a hipótese de extinção por vontade unilateral, estabelecendo previamente e de comum acordo uma solução equitativa" (Comentários ao novo Código Civil. Coordenador Sálvio de Figueiredo Teixeira. Rio de Janeiro: GEN-Forense, 2011, vol. VI, tomo II, pg. 365)

${ }^{19}$ Cfr., RUy Rosado De AgUiAR JR. (obra e local citados), PAUlo NADER (Curso de direito civil. $6^{\text {a }}$ edição. Rio de Janeiro; GEN-Forense, 2012, vol. 3, pgs. 151/152) e CARLOS ROBERTO GONÇALVES (Direito Civil Brasileiro. $9^{\mathrm{a}}$ edição. São Paulo: Saraiva, 2012, vol. 3, pg. 207).
}

Revista de Direito Brasileira | São Paulo, SP | v. 16 | n. 7 | p. 291 - 304 | jan./abr. 2017 
A adequada alocação de riscos contratuais, diante do parágrafo único do art. 473 do Código Civil, pressupõe especial cautela dos empresários, na negociação de contratos de colaboração, visando neutralizar o desequilíbrio que o direito vigente pode ocasionar. Interpretações consistentes da norma apontam para seu caráter supletivo e até mesmo para a inaplicabilidade aos contratos empresariais, mas, como visto, por serem mediatizadas, elas não conseguem servir de parâmetro na aferição da previsibilidade das decisões judiciais.

\section{CONCLUSÃO: A IMPORTÂNCIA DA SEGURANÇA JURÍDICA DO AMBIENTE DE NEGÓCIOS}

O aumento da segurança jurídica no ambiente de negócios brasileiro interessa, sobretudo, aos consumidores e trabalhadores (à "comunidade", pode-se dizer de modo genérico) e apenas secundariamente aos empresários e investidores. Estes, como afirmado, são disputados pelos diversos países interessados no incremento de suas economias. Se não se sentem suficientemente seguros em determinada jurisdição, os investidores podem simplesmente redirecionar a atenção para outras, sem maiores dificuldades. Consumidores e trabalhadores, porém, no mais das vezes, consomem e trabalham onde residem, não sendo a mudança de país uma opção sempre disponível ou fácil.

Convém frisar que ambientes de negócios que inspiram menos segurança jurídica não estão, por isso, necessariamente fora do círculo de interesse dos investidores. Se assim fosse, aliás, seria até mesmo mais imediata a percepção da necessidade e urgência de o país se aparelhar para competir melhor pelos investidores. A questão, contudo, é bem mais complexa. A segurança jurídica é apenas de um dos vários quesitos levados em consideração, nos cálculos dos investidores que antecedem a decisão quanto ao destino do aporte. Ademais, há os investidores que estão à procura exatamente de ambientes de negócio mais arriscados; chamemo-los de "arrojados", em contraposição àqueles que não estão dispostos a assumirem riscos excessivos, os "conservadores".

Pois bem. Ambientes de negócio sem consistente segurança jurídica não atraem os investidores conservadores, mas podem se mostrar muito atraentes aos arrojados. Qual o problema, então, se, de um modo ou de outro, os investimentos chegam? O problema está nas características próprias dos investimentos destinados a ambientes mais arriscados. Fórmula milenar, enraizada no comércio fenício, associa diretamente riscos e retornos esperados. Quem assume riscos maiores, não se contenta com retornos módicos. O investidor arrojado atraído por ambientes de negócio sem segurança jurídica praticará preços mais elevados, nos produtos ou serviços que oferece ao mercado. Mesmo os conservadores veem-se forçados a seguir esta lógica, para embutirem em seus preços uma taxa de risco associado à insegurança jurídica. Quer dizer, são os consumidores que, pagando mais caro por produtos e serviços, arcam com as consequências da insegurança jurídica.

Mas não só eles. Também os trabalhadores acabam penalizados. Ambientes de negócios mais arriscados atraem o interesse de uma quantidade menor de investidores. Os arrojados são poucos, quando comparados com os conservadores; e assim é em razão da lei da oferta $e$ demanda. Os retornos mais elevados só podem ser obtidos por quem os busca em segmentos em que não há muita competição. Naquelas atividades em que vários empresários competem, a oferta elevada força os preços para baixo e afasta os arrojados. Quer dizer, ambientes de negócio com insegurança jurídica comportam menos postos de trabalho, em prejuízo do nível dos salários e demais interesses dos trabalhadores.

$\mathrm{Na}$ economia globalizada, em que os investidores têm o mundo todo para investir, portanto, é à coletividade que interessa fundamentalmente a melhoria do ambiente de negócios, com o incremento do grau de segurança jurídica que o direito comercial inspira.Quando assegura 
a alocação de risco legal ou contratualmente definida, nas relações empresariais, é inevitável: o Judiciário protege a própria comunidade.

\section{BIBLIOGRAFIA}

AGUIAR Jr., Ruy Rosado de. Comentários ao novo Código Civil. Coordenador Sálvio de Figueiredo Teixeira. Rio de Janeiro: GEN-Forense, 2011, vol. VI, tomo II.

ALEXY, Robert. Teoria dos direitos fundamentais. Tradução de Virgílio Afonso da Silva. São Paulo: Malheiros, 2008.

ÁVILA, Humberto. Teoria da segurança jurídica. $3^{\text {a }}$ edição. São Paulo: Malheiros, 2014. . Teoria dos princípios - da definição à aplicação dos princípios jurídicos. $13^{\mathrm{a}}$ edição. São Paulo: Malheiros, 2012.

CARRAZZA, Roque. Curso de direito constitucional tributário. 22a edição. São Paulo: Malheiros, 2006

COELHO, Fábio Ulhoa. Curso de direito comercial. 17ª edição. São Paulo: RT, 2016, vol. 3.

FERRAZ, Sérgio e DALLARI, Adilson Abreu. Processo administrativo. $3^{\text {a }}$ edição. São Paulo: Malheiros, 2012.

GONÇALVES, Carlos Roberto (Direito Civil Brasileiro. 9a edição. São Paulo: Saraiva, 2012, vol. 3.

HUCK, Hermes Marcelo. Garantia à primeira solicitação no comércio internacional. Em “Revista de Direito Mercantil”, vol. 84. São Paulo: RT, outubro-dezembro de 1991, pg. 10.

JARDIM, Monica. A garantia autônoma. Coimbra: Almedina, 2002.

KNUTS, Mårten e KOLSTER, Thomas. Supreme Courts in the nordics pierce the corporate veil - is the limited liability of the shareholders at risk? Em "Business Law International". London: International Bar Association, vol. 17(3), pgs. 253/258.

MARTINS, Ives Gandra da Silva (Coord.). Segurança jurídica em matéria tributária. Porto Alegre: Lex Magister - CEU-IICS, 2016. 
MENDES, Gilmar. Curso de direito constitucional. Em coautoria com Inocêncio Mártires Coelho e Paulo Gustavo Gonet Branco. $3^{\text {a }}$ edição. São Paulo: Saraiva, 2008.

MENDES, Maria Cristina Varalla e RODRIGUEZ, Caio Farah. Notas sobre a alocação de riscos e garantias contratuais. Em Fundamentos e Princípios dos contratos empresariais. Coordenador Wanderley Fernandes. São Paulo: Saraiva-FGV, 2007.

NADER, Paulo. Curso de direito civil. $6^{\text {a }}$ edição. Rio de Janeiro; GEN-Forense, 2012, vol. 3.

NIYAMA, Jorge Katsumi e GOMES, Amaro L. Oliveira. Contabilidade de instituições financeiras. São Paulo: Atlas, 2000.

ROCHA, Sílvio Luis Ferreira da. Manual de direito administrativo. São Paulo: Malheiros, 2013.

SERIK, Rolf. Rechtsform und Realität juristischer Personen. $2^{\mathrm{a}}$ edição. Tübigen: Mohr, 1980.

SILVA, Virgílio Afonso da Direitos Fundamentais - conteúdo essencial, restrições e eficácia. $2^{\mathrm{a}}$ edição. São Paulo: Malheiros, 2010.

TAVARES, André Ramos. Curso de direito constitucional. 8ª edição. São Paulo: Saraiva, 2010.

VEIGA, Vasco Soares da. Direito bancário. Coimbra: Almedina, 1994.

WALD, Arnoldo. A garantia à primeira demanda no direito comparado. Em "Revista de Direito Mercantil” vol. 66. São Paulo: RT, abril-junho 1987. 